\title{
Think global
}

\section{'Virtual globe' software is transforming our ability to visualize and hypothesize in three dimensions. Educators take note.}

$1 /$ illions of people across the world are zooming in from space, flying across continents, and swooping over mountains and through cities, thanks to Google Earth, NASA's World Wind and other free virtual globes.

The ability to model the Earth in exquisite three-dimensional detail was previously only approached on the desktops of professional users of geographical information systems (GIS). But even they were unable to publish high-resolution globes on the Internet, because of the sheer volume of the data - a globe with a resolution of one metre would take years to download using even a fast Internet connection. Virtual globes overcome this problem with elegant engineering, using a tiling structure that sends progressively higherresolution data as one zooms in. This and other tricks drastically reduce the size of file transfers, and allow visualization with almost zero latency on a decent broadband connection.

Scientists are already experimenting with these tools to showcase their research to the public in visually appealing ways and to speed responses to natural disasters (see pages 776 and 787). Ultimately, such accurate digital representations promise to anchor and unify much digital information about the Earth, while also helping to integrate the efforts of researchers from many disciplines.

Rita Colwell, a microbiologist and former head of the National Science Foundation, has described GIS as the "ultimate, original, multidisciplinary language ${ }^{\prime}$. Her own research is a shining example. Realizing that cholera epidemics spread inland from the coast, she correlated them with seasonal plankton blooms, discovering on the way that the Vibrio cholerae bacteria that cause cholera associate with gravid copepods, helping to break open their egg sacs by secreting chitinases. She went on to use remote sensing for a global predictive system for epidemics. As she has said, a major need is "to appreciate the complex reactions that characterize ecosystems - it is too complex for anyone discipline".

By making it child's play to share and view multiple large data sets, virtual globes lower the barrier to entry for scientists with little GIS experience. Visualization itself can lead to new insights. Having tasted such visualizations, many researchers will be tempted to go beyond them to exploit the full capacities of GIS science to analyse vast arrays of disparate data in their spatial context.

The opportunities and power of GIS are expanding rapidly because of converging technological trends. The quality of spatial and remote-sensing data is sharply increasing in many fields, as are data-mining techniques, which can help lead to new hypotheses. Mobile global positioning system (GPS) devices are raising the prospect of collecting locationspecific information quickly and cheaply, making it possible for large networks of intelligent devices to map and monitor a release of toxic gas, for example, and predict its spread.

To meet such spatial oppor"Scientists are already experimenting with these tools to showcase their research to the public and to speed responses to natural disasters." tunities, researchers and students will need training in spatial sciences. The risks of using computational packages as 'black boxes' are well known, and are even greater, if anything, with GIS. As GIS experts have noted: ${ }^{\alpha}$ The production of visually appealing, even statistically sound, results that do not reveal anything useful about either pattern or process is perhaps the greatest danger facing newcomers to this powerful technology" (Nature Rev. Microbiol. 1, 231-237;2003). It is therefore encouraging to note that last week the US National Academy of Sciences called for the introduction of "spatial thinking", including GIS, into school curricula, and for government research agencies to launch research into the nature of the cognitive processes involved in such thinking.

Many outstanding minds, including Einstein, Faraday, Kekulé and Heisenberg, have attributed their key insights to the ability to think spatially. Let's hope that the upcoming generation of threedimensional gamers and Google Earthers will yield even more spatially adept prodigies ready to confront global challenges.

\section{It's academic}

\section{The development of scientific academies could help to put science to work in Africa.}

\rceil he medical, scientific and environmental challenges facing the continent of Africa can seem simply overwhelming. Some of them, such as the provision of health care and basic scientific education, are bound to be expensive to address. But others could be tackled by less expensive and more subtle means: the development of properly functioning scientific academies in African nations.
The US National Academy of Sciences, under its former president Bruce Alberts, began a laudable, long-term project to build up the prowess of such academies in three African nations: Nigeria, South Africa and Uganda. But as a meeting in Amsterdam of African academy officials heard earlier this month, rapid progress could be made in other countries too, if scientists, government officials and donor nations would step up to the plate.

Self-elected bodies of accomplished scientists make a significant contribution to public discourse in most wealthy nations. In Britain, the Netherlands and the United States, for example, academies have long played a broadly productive role in raising the level of public discussion on technical issues. They also provide governments 
with advice on matters as diverse as public transport and nuclearwaste disposal.

There is an opportunity, in the rapidly developing polities of modern Africa, for similar academies to emerge there. The existing academies have had little influence. They were not involved, for example, in shaping the New Partnership for Africa's Development (NEPAD), an important collaboration between Africa's governments whose plans include the creation of research centres and networks to tackle continent-wide woes, such as malaria and poor water supply.

This lack of clout has been equally apparent at the national level. In 2002, for example, when Zambia decided to reject food aid from the United States on the grounds that it contained genetically modified maize, its president Levy Mwanawasa appealed on television for the country's scientists to help him out. The broadcast was the first Zambia's science academy knew of his interest, as there was no established channel for communication between the academy and his government in Lusaka.

There is no good reason why this state of affairs should persist. Academies are not particularly expensive to run, and they already exist in many African countries. Although their membership is small and their expertise is in many cases limited, there are areas in which they could be helping their respective governments right now. What is often missing are the political skills needed to get such advice heard, in government or in the media.

The participants in the National Academy's ten-year project, supported by $\$ 20$ million from the Bill \& Melinda Gates Foundation, are already showing the way ahead, particularly with regard to health issues. In Uganda, for example, scientists will be trained to work effectively with media outlets to get their message across, and regular meetings will be arranged between researchers, businesses, government officials and politicians to discuss their responses to malaria.

For this model to make headway, of course, political leaders need to be convinced of its value. That will only happen in nations with leaders who are genuinely accountable to their electorates, and where a reasonably free press permits public discussion of the issues.

Progress on both these fronts remains patchy, but scientists can strengthen their prospects of being heard by working to build up the effectiveness of their own academies, while finding proactive means of getting their message out to politicians, the media and the wider public. Greater expertise will then be
"Determination from scientists to maketheir voices heard could go a long way towards bringing their expertise to bear on African problems." brought to bear, particularly with regard to pressing African issues, such as standards in education at all levels.

Even in the best of circumstances, it is extremely difficult to get politicians to listen to independent scientific advice. African capitals do not enjoy the best of circumstances. Yet the political situation in many of these capitals is fluid, and determination from scientists to make their collective voices heard could go a long way towards bringing their expertise to bear on African problems.

\section{NASA in reverse}

\section{The US space agency's relationship with scientists is hitting a new low.}

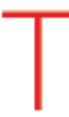

he NASA public-affairs office has this month been accused of trying to censor one of its most eminent climate researchers, James Hansen of the Goddard Institute for Space Studies in New York. And more evidence of press releases being doctored for political ends at the space agency is likely to emerge, disturbing everyone who values the free flow of scientific information to the public.

But the Hansen debacle is just one element of the increasingly adversarial relationship that is developing between NASA and the research community. The sour mood was apparent at last month's American Astronomical Society meeting in Washington DC, when NASA's science chief Mary Cleave told assembled scientists that her most important "stakeholders" were the White House and Congress. Cleave's real (if unintentional) message was clear: don't expect NASA to advocate research, as we work for other interests.

Scientists were also dismayed at how fast NASA administrator Mike Griffin reneged on a promise made last autumn not to take "one thin dime" from space science to address the budget problems of the space shuttle and the space station. At his budget news conference on 6 February, Griffin confessed to doing just that, shifting $\$ 2$ billion over five years from research to the astronaut programme.

The cuts to science were deep, and they were decided behind closed doors. Take the research and analysis grants that fund the basic intellectual work underlying NASA's space missions. Previous NASA administrators, recognizing that many space scientists rely on these grants to stay in business, kept the grant programme healthy. But the new budget slashes research grants by $15-25 \%$, and by even more in areas such as astrobiology. And NASA is yet to give details of how deep the cuts actually are.

Nor did the agency bother to inform some scientists that their projects were being axed. One investigator who was awaiting final approval of her NuSTAR Explorer mission after two years of hard work heard Cleave announce its cancellation at a press conference. Such a cavalier approach to communication is prompting outrage in the community.

NASA is undergoing a historic shift in direction without
"NASA is undergoing a historic shift in direction without consulting scientists or paying attention to their advice." consulting scientists or paying attention to their advice. Projects with great appeal to scientists and to the public - including the search for planets around other stars and the study of dark energy - are being abandoned so that NASA can return astronauts to the moon half a century after the Apollo landings.

Griffin still enjoys some good will from researchers who know him. They understand that his overall budget is set by the White House, and that he is only cutting science reluctantly. But that good will is soon going to vanish if the Bush administration continues to steer the nation's $\$ 17$-billion space programme on such a controversial course, without listening to alternative views of what NASA should be doing. 